\title{
$\mathrm{KVMF}$ 전술네트워크에서 링크 품질에 기반한QoS 향상 방안
}

권 구 형*, 정 현 숙", 임 원 기", 윤 영 득", 김 상 수", 이 상 진"*

\section{QoS Enhancement Based on Link Quality in Tactical Data Link of KVMF}

\author{
Koo-Hyung Kwon*, Hyun-Sook Jeong*, Won-Gi Lim*, Young-Deuk Yoon*, \\ Sang-Soo Kim*, Sang-Jin Lee ${ }^{* *}$ \\ 요 약
}

본 논문은 $\mathrm{NCW}$ 를 지원하는 $\mathrm{KVMF}$ 전술네트워크 환경에서 송신지와 목적지 사이에 다중경로가 존재할 때, 기 존의 MIL-STD-188-220 프로토콜에서 사용하는 DTR 비트를 활용하여 QoS를 향상시킬 수 있는 알고리즘을 제안 한다. MIL-STD-188-220 프로토콜은 경로의 품질을 상대적으로 평가할 수는 있지만, QoS에 맞는 최적의 경로를 제공하지 못하는 문제점을 갖고 있다. 이를 해결하기 위해 전송을 완료한 경로의 지연시간, 처리량, 신뢰성을 측정 하여 토폴로지 테이블에 반영하고, 경로 선택에 활용하도록 알고리즘을 설계하였다. 제안한 알고리즘은 OPNET 시 뮬레이터를 이용하여 성능을 평가하였으며, 악화된 통신 환경에서 MIL-STD-188-220에 비하여 성능이 향상됨을 확인하였다.

Key Words : KVMF, MIL-STD-188-220, Q0S, DTR

\section{ABSTRACT}

This paper suggests an algorithm to improve QoS by using DTR bit employed in the MIL-STD-188-220 protocol, when there is a multi-path between source and destination in the environment of KVMF tactical network supporting NCW. The MIL-STD-188-220 protocol can evaluate the link quality relatively but it cannot support optimal path selection for QoS. In order to solve this problem, we design an algorithm for selecting path using topology table which reflects measured DTR of path after the completion of transmission. The performance of the proposed algorithm has been evaluated by OPNET simulator. As a result of the simulation, it is found that QoS of proposed algorithm is enhanced higher than that of the MIL-STD-188-220 in the aggravated communication environment.

\section{I. 서 론}

현대전의 양상은 화력·기동의 플랫폼 중심에서 네
트워크 중심전(NCW : Network Centric Warfare)으 로 바뀜에 따라 보다 많은 전장정보를 신속하게 수집, 종합 분석하여 실시간 전장상황을 파악, 신속하게 지

- First Author : 국방과학연구소 2기술연구본부 국방사이버기술센터, koohyung@add.re.kr, 정회원

* 국방과학연구소 2 기술연구본부

** (주)유큐브 기술연구소

논문번호 : KICS2013-08-373, 접수일자 : 2013년 8월 30일, 심사일자: 2013년 10월 28일, 최종논문접수일자 : 2014년 2월 4일 
휘결심하고, 적보다 먼저 타격하기 위한 지휘·통제 결 심지원체계가 필요하다 ${ }^{[1]}$. 그러나 현재 한국군의 무기 체계는 다양한 전술데이터링크를 사용함에 따라 상호 무기체계간의 원활한 연동 및 상호운용이 어렵기 때 문에 신속한 지휘·통제 결심을 하는데 많은 제약이 따 른다. 이러한 문제점을 해결하기 위하여, 최근 들어 다양한 형태의 통합 전술 데이터링크가 개발되고 있 으며, 한국군은 $\mathrm{NCW}$ 를 대비하여 한국형 가변 메시지 포맷 (Korean Variable Message Format: KVMF) 전 술 데이터링크 기술 확보를 위하여 2004년부터 연구 개발을 추진 중에 있다 ${ }^{[2-4]}$.

한국군과 미군에서 사용하는 대표적인 Ad-hoc 프 로토콜인 MIL-STD-188-220은 FM무전기를 사용하 여 중계기능을 수행할 수 있도록 해주며, OSI 7 계층 중 하위 3계층만을 정의하고 인터넷 계층(Internet Layer)이상의 계층은 상용 방법을 그대로 사용한다. MIL-STD-188-220 프로토콜은 수행되는 서비스에 관 한 정보를 송수신하기 위하여 상위 및 하위 계층 간에 상호 작용을 한다. 이러한 상호 작용을 통하여 전달되 는 매개변수로부터 수행되는 서비스가 요구하는 서비 스 품질(QoS: Quality of Service)을 확인할 수 있다. QoS는 인트라넷 헤더의 DTR(Delay, Throughput, Reliability) 비트로 표시하며, 우선도(Precedence)와 조합되어 데이터 링크 계층에서 운용 타입을 선택하 여 해당 서비스에 대한 $\mathrm{QoS}$ 를 보장하도록 설계되었 다 ${ }^{[5,6]}$. 하지만 송신지와 목적지 사이에 다중경로가 존 재하는 환경에서는 데이터 링크 계층에서 운용 타입 을 결정하더라도 $\mathrm{QoS}$ 를 보장할 수 있는 경로를 선택 할 수 있는 지표를 제공하지 못하는 한계가 있다.

이를 극복하기 위해 본 논문에서는 다중 경로에서 MIL-STD-188-220 프로토콜이 선택적으로 제공하는 링크 품질(Link Quality) 기능 및 명확하지 않은 품질 측정 방안을 개선하기 위한 알고리즘을 제안하였다. 상대적인 수치로 통합적인 품질을 평가하는 Link Quality 기능을 ${ }^{[5]}$ 구체적인 수치로 요구사항에 따른 품질을 제공함으로써 최적의 경로를 선택하게 되고, 이는 전체 망 성능을 향상시킬 수 있다.

본 논문의 구성은 2장에서 군 환경에서의 Ad-Hoc 네트워크 및 MIL-STD-188-220 프로토콜의 인트라넷 계층에 대하여 간략히 기술하고, 3장에서는 제안하는 알고리즘의 성능에 대한 평가 및 분석을 시뮬레이션을 통해 확인한다. 마지막으로 4장에서는 결론을 맺는다.

\section{II. 본 론}

본 장에서는 군 환경에서의 Ad-Hoc 네트워크 및 MIL-STD-188-220 프로토콜에 대하여 간략히 기술하 고, 제안하는 알고리즘에 대하여 설명한다.

\section{1 군 환경에서의 Ad-Hoc 네트워크}

현재 육군은 네트워크 체제를 기반으로 지상 전술 C4I (Command, Control, Computer, Communication and Intelligence) 시스템을 정비 및 실현화 중에 있다. 지휘관이 전장에서 성공적인 지휘 및 통제를 하기 위 해서는 정확한 시간과 장소에 정확한 정보를 필요로 하며, 통신 수단을 이용하여 신속히 정보를 전파 또는 송신해야 한다. 또한 같은 망에 속한 단말기들이 데이 터를 전송할 때, 데이터 충돌 상황이 발생하지 않아야 한다. 군 환경에서의 각각의 노드는 모두 이동성이 있 는 모바일 노드이기 때문에 각각의 단위부대에 의한 $\mathrm{Ad}-\mathrm{Hoc}$ 네트워크를 기반으로 $\mathrm{NCW}$ 환경이 완성될 수 있을 것이다. 그러나 이러한 모바일 노드의 이동을 전제로 구성된 Ad-Hoc 네트워크라 할지라도 각각의 모바일 노드가 가지고 있는 이동성에 의한 많은 제약 과 전체 네트워크의 불안정성을 완벽하게 극복하지는 못하고 있는 실정이다. 특히 산악 지형이 많은 우리나 라의 특성상 이동 노드의 일부 또는 전체가 수시로 네 트워크에 나타나거나 사라질 수도 있는 상황을 고려 하여 본 연구에서는 특정 경로에 대해 폐쇄구간을 지 정하여 유사한 환경이 될 수 있도록 고려하였다 ${ }^{[7-9]}$.

\subsection{MIL-STD-188-220 프로토콜}

\subsection{1 토폴로지 업데이트 및 경로 선택}

토폴로지 업데이트 기능은 네트워크내 노드가 자신 의 개별 라우팅 트리를 이웃노드들에게 멀티캐스트하 여 토폴로지 정보를 얻고 관리하는 기능을 수행한다. 토폴로지 업데이트 데이터 구조는 그림 1 과 같다 ${ }^{[5]}$.

그림 2에서 Node Status Byte는 토폴로지 업데이 트 메시지를 송신 또는 중계한 발신자의 주소(인트라 넷 헤더의 발신자 주소에 나타난 주소)와 그 선행 노 드 사이의 링크를 묘사한다.

Node Status Byte에서 LINK QUALITY 필드는 해당 노드와 선행 노드 사이의 링크의 품질 정보를 나 타낸다. 링크의 품질을 알 수 없는 경우 연결 품질이 0 으로 설정된다. 링크 품질 값이 증가할수록 링크의 상태는 좋지 않다는 것을 나타낸다. HOP LENGTH 필드는 자신과 해당 노드의 거리를 나타내며, $\mathrm{NR}$ 필 


\begin{tabular}{|c|c|c|c|c|c|c|c|}
\hline $\begin{array}{c}M S B \\
7\end{array}$ & 6 & 5 & 4 & 3 & 2 & 1 & $\begin{array}{c}L S B \\
0\end{array}$ \\
\hline \multicolumn{8}{|c|}{ Topology Update Length } \\
\hline \multicolumn{8}{|c|}{ Topology Update ID } \\
\hline \multicolumn{8}{|c|}{ Node 1 Address } \\
\hline \multicolumn{8}{|c|}{ Node 1 Status Byte } \\
\hline \multicolumn{8}{|c|}{ Node 1 Predecessor Address } \\
\hline \multicolumn{8}{|c|}{ Node 2 Address } \\
\hline \multicolumn{8}{|c|}{ Node 2 Status Byte } \\
\hline \multicolumn{8}{|c|}{ Node 2 Predecessor Address } \\
\hline \multicolumn{8}{|c|}{ Node N Address } \\
\hline \multicolumn{8}{|c|}{ Node N Status Byte } \\
\hline \multicolumn{8}{|c|}{ Node N Predecessor Address } \\
\hline
\end{tabular}

그림 1. 토폴로지 업데이트 데이터 구조

Fig. 1. Topology Update Data Structure

\begin{tabular}{|c|c|c|c|c|c|c|c|}
\begin{tabular}{|c|c|c|c|}
$M S B$ \\
7
\end{tabular} & 6 & 5 & 4 & 3 & 2 & 1 & 0 \\
\hline QUIET & NR & \multicolumn{2}{|c|}{ HOP LENGTH } & \multicolumn{2}{|c|}{ LINK QUALITY } \\
\hline
\end{tabular}

그림 2. 노드 상태 바이트

Fig. 2. Node Status Byte

드는 중계 기능에 대하여 활성/비활성을 나타낸다. 마 지막으로 QUIET 필드는 설정이 되어 있는 경우 어떠 한 트래픽도 송신하지 않는다. LINK QUALITY 필드 가 7로 설정되어 있으면, 고정 노드이다. 고정 노드는 데이터 링크 주소가 미리 할당 되고, 네트워크에 들어오 고 나감으로써 인트라넷 토폴로지에 영향을 미치지 않 는다. 표 1은 토폴로지 링크 품질 값에 대한 표이다 ${ }^{[5]}$.

MIL-STD-188-220 프로토콜에서 경로 선택과정은 토폴로지 테이블을 기반으로 결정되며 절차는 다음과 같다. 토폴로지 업데이트 메시지를 수신한 지국은 각 필드를 확인하여 토폴로지 테이블을 작성한다. 토폴로 지 테이블은 인근 지국들의 정보를 저장하며, 상위 계 층에서 전송을 요청하는 메시지가 도착하면 목적지 주소까지의 경로를 탐색하는데 사용된다. 다중 경로가 존재하면 기본적으로 최소 홉 수(shortest path) 기반

표 1. 토폴로지 링크 품질 값

Table 1. Topology Link Quality Value

\begin{tabular}{c|c}
\hline Link Quality & Description \\
\hline 0 & Unknown \\
\hline 1 & Best Link \\
\hline 2 & - \\
\hline 3 & - \\
\hline 4 & - \\
\hline 5 & - \\
\hline 6 & Worst Link \\
\hline 7 & Static Node \\
\hline
\end{tabular}

으로 경로를 선택한다. 동일한 홉 수의 경로가 존재하 는 경우 표 1 의 정보를 사용하여 경로를 결정할 수 있 다. 하지만 링크 품질 기능을 선택적(optional)으로 제 공하며 ${ }^{[5]}$, 링크 품질의 수치는 정의하고 있으나 측정 방안은 구현의 쟁점 중 하나이다. 즉, 명확하지 않은 측정 방안으로 인해 링크 품질 기능은 개발사에 의존 하고 있는 상태이다. MIL-STD- 188-220 프로토콜에 서 링크 품질을 사용하지 않는 경우에 동일한 홉 수를 갖는 경로가 다수 존재하면, 링크 품질을 알 수 없기 때문에 일반적으로 후보 경로를 순차적으로 변경하여 전송을 시도한다.

\subsection{2 계층 간 상호 작용}

MIL-STD-188-220 프로토콜은 OSI 7 계층 중 하 위 3계층만을 정의하고 인터넷 계층(Internet Layer) 이상의 계층은 상용의 방법을 그대로 사용하기 때문 에 계층 간의 정보 교환은 상호작용을 통하여 서비스 요청 및 수행에 관한 정보를 공유한다. 이러한 계층 간 상호 작용은 프리미티브(Primitive)를 사용하여 수 행되고, 데이터의 송수신 및 통신환경의 정보를 전달 하기 위해 세 종류(IL-Unitata Request, IL-Unitdata Indication, IL-Status Indication)의 프리미티브를 사 용한다 ${ }^{[5,10]}$. 그러나 인터넷 계층 이상에서는 상용의 프로토콜을 사용하기 때문에 앞에서 설명한 방법과는 다른 방법을 통하여 계층 간에 정보를 교환한다. 그리 고, $\mathrm{SNDCF}$ (Subnetwork Dependent Convergence Function)를 정의하고 있으며, IP 기반 서비스가 특정 서브네트워크 내에서 제공될 수 있도록 필요한 정보 를 생성 또는 변환하는 기능을 수행한다. SNDCF를 통해 MIL-STD-188-220 프로토콜을 사용하여 IP 기 반의 서비스를 제공할 수 있다. 하지만 이기종의 프로 토콜을 연동하면서 발생할 수 있는 문제는 구현의 쟁점 이다. IP 기반의 서비스와 MIL-STD-188-220 프로토 콜을 함께 운용하는 경우 개별적인 라우팅 정책을 수행 하기 때문에 문제가 발생할 수 있다. 본 연구에서 라우 팅 정책은 MIL-STD-188-220 프로토콜을 준수한다.

\section{3 제안 사항}

MIL-STD-188-220 프로토콜의 인트라넷 계층에서 는 송신지와 목적지 사이에 동일한 홉 수를 가지는 경 로가 다수 존재하는 환경에서는 $\mathrm{QoS}$ 를 최대한 보장 할 수 있는 경로를 선택할 수 없는 한계를 가지고 있 다. 이러한 문제점을 해결하기 위하여 동일한 홉 수를 가지는 경로가 다수 존재하는 경우, 사용자가 요구하 는 $\mathrm{QoS}$ 를 확인하여 최적의 경로를 선택할 수 있는 방 
안을 제안한다. 제안하는 방안은 우선적으로, 경로의 품질을 측정하기 위하여 $\mathrm{ACK}$ 를 요구하는 프레임을 전송하는 경우 수신되는 $\mathrm{ACK}$ 로부터 지연시간 및 전 송된 프레임의 크기, 재전송 횟수 등의 정보를 확인한 다. 확인된 정보로부터 해당 경로의 품질을 판단할 수 있도록 DTR 파라미터를 설정하여 토폴로지 테이블을 구성한다. 구성된 토폴로지 테이블은 주기적으로 인근 노드로 전파 및 갱신된다. 전송을 시도하는 경우 메시 지의 DTR 필드를 확인하여 사용자가 요구하는 $\mathrm{QoS}$ 를 판단한 후, DTR 기반의 토폴로지 테이블을 확인하 여 최적의 경로를 선택한다. 제안한 방법을 적용하는 경우 품질이 우수한 경로를 우선적으로 선택하여 지 연시간의 단축, 성공률 및 처리량을 개선할 수 있다. 또한, 품질이 우수한 경로가 다수 존재하는 환경에서 도 사용자가 요구하는 $\mathrm{QoS}$ 를 최대한 보장할 수 있다.

제안한 방안은 3 개의 세부 방안으로 구성된다. 첫 째는 링크 상태 라우팅 기술을 지원하기 위한 DTR 기반 링크 품질 설정 알고리즘, 둘째는 설정된 링크 품질 정보를 저장 및 공유하기 위한 DTR 기반 토폴 로지 테이블 생성 기능, 마지막으로 세 번째는 다중 경로가 존재하는 경우 서비스가 요구하는 $\mathrm{QoS}$ 를 고 려하여 최적 경로를 선택하는 DTR 기반 다중 경로 선택 알고리즘이다.

\subsubsection{DTR 기반 링크 품질 설정 알고리즘}

데이터 링크 계층에서 확인 응답을 요구하는 프레임 을 수신하는 지국은 이에 대한 응답으로 $\mathrm{ACK}$ 를 구성 한다. 메시지를 송신한 지국은 확인 응답이 도착하면 경로의 성능 지표를 측정하기 위하여 송신에 소요된 지 연시간과 프레임의 크기, 송신 시도 수, 확인 응답 수신 수를 확인한다. 확인된 정보는 토폴로지 테이블의 링크 품질을 갱신하기 위하여 DL-DTR Indication 프리미티 브를 만들어 상위 계층(Intranet Layer)으로 전달한다. 최대 재송신 시도 후 확인 응답을 수신하지 못하는 경 우에는 지연시간은 최대 재송신 타이머의 시간을 적용 하고, 프레임 크기는 0 으로 적용하여 평균 지연시간 및 누적 처리량을 갱신한다. 그림 3은 DL-DTR Indication

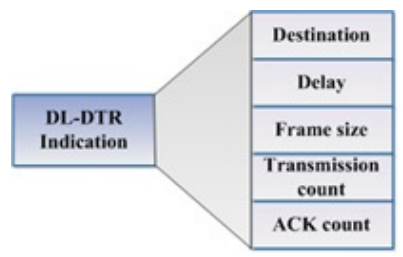

그림 3. DL-DTR 지시 프리미티브

Fig. 3. DL-DTR Indication Primitive

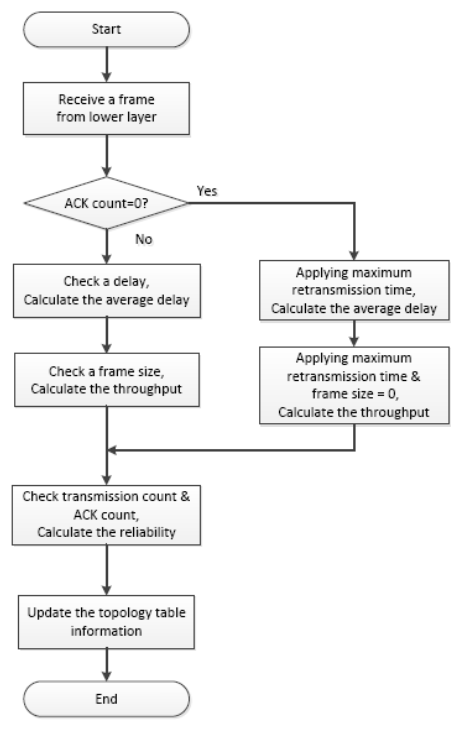

그림 4. 링크 품질 설정 알고리즘

Fig. 4. Path quality setting algorithm

프리미티브의 구성도를 나타내며, Destination, Delay, Frame size, Transmission count, ACK count 파라미 터로 구성된다.

그림 4는 데이터 링크 계층으로부터 수신된 프리미 티브로부터 링크 품질을 설정하는 과정을 나타낸다.

하위 계층(Data Link Layer)에서 DTR 프리미티브 가 수신되면 인트라넷 계층에서는 평균 지연시간, 누 적 처리량, 신뢰성 정보를 갱신한다. 확인 응답의 수 신 여부로 송신 성공 여부를 판단한 후, 성공한 경우 프리미티브 파라미터의 지연 시간과 프레임 크기를 사용하여 평균 지연 시간 및 처리량 정보를 갱신한다. 확인 응답을 수신 하지 못한 경우에는 지연시간을 최 대 재송신 타이머의 시간으로 적용하고, 프레임 크기 는 0 으로 적용하여 평균 지연시간 및 누적 처리량을 갱신한다. 신뢰성은 송신을 시도한 총 횟수와 확인응 답을 받은 횟수를 사용하여 계산하여 토폴로지 테이 블에 반영한다.

\subsubsection{DTR 기반 토폴로지 테이블}

제안하는 DTR 토폴로지 테이블은 MIL-STD-188220 프로토콜을 참조하여 Node Address, Node Predecessor, Hops, Cost, NR, Quiet로 구성된다. Cost 필드는 DTR 요구사항에 맞는 경로를 선택할 수 있도록 Average Delay, Cumulative Throughput, Reliability 서브 필드를 구성하여 각 경로의 평균 지 연시간, 누적 처리량, 신뢰성을 정보를 저장한다. 이 
때, 생성되는 프레임은 MIL-STD-188-220 프로토콜 의 프레임 포맷 형식을 준수한다. 이를 통해 최종적으 로 생성되는 DTR 기반 토폴로지 테이블의 활용 예는 그림 5 및 표 2에서 나타내는 것과 같다.

구성된 토폴로지 테이블은 주기적으로 전송하는 토 폴로지 업데이트 메시지를 생성하여 인근 노드에게 전파된다. 토폴로지 업데이트 메시지의 구성은 그림 1 과 같으며, 그림 2의 "LINK QUALITY" 필드는 그림 5의 "Cost" 필드(3 비트: Average Delay(1비트), Cumulative Throughput(1비트), Reliability(1비트))로 대체된다. 대체된 Cost 필드는 해당 서브 필드의 정보 변경 여부를 의미하며, ' 1 '로 설정되면 해당 파라미터 의 값의 갱신, ' 0 '으로 설정된 경우는 변동이 없음을 의미한다. ' 1 '로 설정된 파라미터의 값을 토폴로지 업 데이트 메시지 바로 뒤에 추가(option) 필드를 구성하 여 값을 전송하고, ' 0 '으로 설정된 경우는 토폴로지 업 데이트 메시지만 전송한다. 수신 노드에서 "Cost"필드 의 각 비트에서 ' 1 '의 값을 확인하면, 추가 필드에서 값을 확인하여 토폴로지 테이블을 갱신한다. 추가 필 드 구성은 지연시간, 누적처리량, 신뢰성 파라미터들만 가능하고, 추가 필드의 구성 및 크기는 구현의 쟁점 중 하나로써 구현 방안에 따라 달라질 수 있다. 본 제안방 법에서는 지연시간, 누적 처리량, 신뢰성은 정수 값으 로 스케일링 하여 각각 1 바이트로 구성된다.

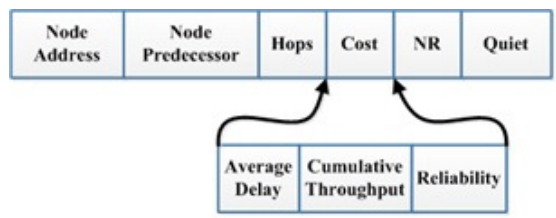

그림 5. DTR 서브 필드 구성

Fig. 5. DTR subfield configuration

표 2. DTR 기반 토폴로지 테이블

Table 2. Topology Table base on DTR

\begin{tabular}{c|c|c|c|c|c}
\hline \multirow{2}{*}{$\begin{array}{c}\text { Node } \\
\text { Address }\end{array}$} & \multirow{2}{*}{$\begin{array}{c}\text { Node } \\
\text { Predecessor }\end{array}$} & HOPs & \multicolumn{3}{|c}{ Cost } \\
\cline { 4 - 6 } & $\begin{array}{c}\text { Average } \\
\text { Delay }\end{array}$ & $\begin{array}{c}\text { Cumulative } \\
\text { Throughput }\end{array}$ & Reliability \\
\hline B & $\mathrm{A}$ & 1 & $5.0 \mathrm{~s}$ & $500 \mathrm{Kbps}$ & $95 \%$ \\
\hline $\mathrm{C}$ & $\mathrm{A}$ & 1 & $4.0 \mathrm{~s}$ & $400 \mathrm{Kbps}$ & $96 \%$ \\
\hline $\mathrm{D}$ & $\mathrm{A}$ & 1 & $6.0 \mathrm{~s}$ & $400 \mathrm{Kbps}$ & $96 \%$ \\
\hline $\mathrm{E}$ & $\mathrm{B}$ & 2 & $11.0 \mathrm{~s}$ & $200 \mathrm{Kbps}$ & $85 \%$ \\
\hline $\mathrm{E}$ & $\mathrm{C}$ & 2 & $14.0 \mathrm{~s}$ & $400 \mathrm{Kbps}$ & $83 \%$ \\
\hline $\mathrm{E}$ & $\mathrm{D}$ & 2 & $13.0 \mathrm{~s}$ & $300 \mathrm{Kbps}$ & $86 \%$ \\
\hline
\end{tabular}

2.3.3 DTR 기반 다중 경로 선택 알고리즘 제안하는 DTR 기반 다중 경로 선택 알고리즘은 서
비스의 목적지가 다중 경로를 가지고 있으면 DTR 기 반의 토폴로지 테이블을 참고하여 DTR 요구사항에 맞는 최적의 경로를 선택한다. 그림 6은 다중 경로 선 택 알고리즘의 흐름도를 나타낸다.

상위 계층에서 프레임이 수신되면 토폴로지 테이블 을 탐색하여 목적지까지 다중 경로가 존재하는지 확 인한다. 다중 경로가 존재하는 경우 요구하는 $\mathrm{QoS}$ 를 적용하기 위하여 DTR 요구사항을 확인한다. 서비스 가 요구하는 $\mathrm{QoS}$ 를 적용할 수 있는 경로를 선택하여 프레임을 구성한 후 하위 계층(데이터 링크 계층)으로 프레임을 송신한다. DTR 요구사항이 $000,011,101$, 110,111 일 경우 각 경로의 지연시간, 누적 처리량, 신뢰성을 비교하여 품질이 우수한 항목이 더 많은 경 로를 선택하여 프레임을 구성한다. MIL-STD-188220 프로토콜은 $\mathrm{QoS}$ 를 보장하기 위하여 인트라넷 헤 더의 DTR 필드와 Precedence 필드를 사용하고 있다. DTR과 Precedence의 값을 조합하여 데이터링크 계층 에서 운용 타입을 결정한다.

표 3은 DTR과 Precedence의 조합으로 결정되는 운용 타입을 나타낸다. 표준에서는 DTR 값이 000 , $100,010,001$ 을 구분하고 있으며, 그 외의 값은 000 과 동일하게 사용된다 ${ }^{[5]}$. QoS 클래스는 추후의 필요 해 의해 증가될 수 있으며, 사용하지 않는 값을 사용 함으로써 확장성을 보장하고 있다.

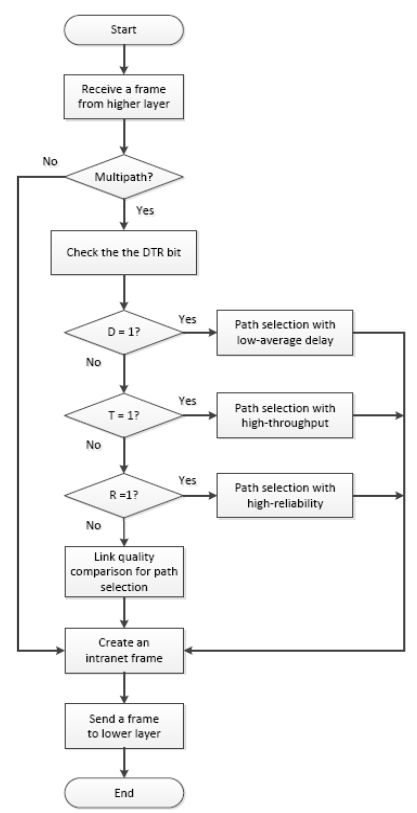

그림 6. DTR 기반 다중 경로 선택 알고리즘

Fig. 6. Multipath selection algorithm based on DTR 
표 3. 데이터 링크 운용 타입 결정 방법

Table 3. Mapping data link operation type

\begin{tabular}{c|c|c}
\hline DTR & Precedence & Station Class A \\
\hline \multirow{2}{*}{000} & Urgent & Type 3 \\
$(\&$ other $)$ & Priority & Type 3 \\
& Routine & Type 1 \\
\hline \multirow{3}{*}{100} & Urgent & Type 3 \\
& Priority & Type 3 \\
& Routine & Type 1 \\
\hline \multirow{2}{*}{010} & Urgent & Type 3 \\
& Priority & Type 3 \\
& Routine & Type 1 \\
\hline \multirow{2}{*}{001} & Urgent & Type 3 \\
& Priority & Type 3 \\
& Routine & Type 3 \\
\hline
\end{tabular}

그림 7은 최종적으로 다중 경로에서 토폴로지 테이 블에 포함된 DTR 성능지표를 사용하여 경로를 선택 하는 방법의 개념을 나타낸다.

송신을 시도하는 노드 $\mathrm{A}$ 의 토폴로지 테이블에 포 함된 DTR 성능지표를 사용하여 경로를 선택하는 방 법을 나타냈다. 송신을 시도하는 노드 $\mathrm{A}$ 는 토폴로지 테이블을 참고하여 목적지 노드까지의 모든 경로를 작성한다. 각 경로는 평균 지연시간(s), 누적 처리량 (bps), 신뢰성(\%)을 산출하고 모든 경로와 비교하여 낮은 지연시간, 높은 처리량, 높은 신뢰성을 가지는 경로를 판단한다. QoS 요구사항이 D 비트가 설정 $(\mathrm{D}=1)$ 된 경우 낮은 지연시간을 가지는 경로를 선택한 다. 경로 별 지연시간의 산출은 전체 경로를 구성하는 각 경로의 지연시간을 저장하고 있는 토폴로지 테이 블을 이용하여 합산한다. 그림 7 의 경로 1 의 지연시간 의 산출은 다음과 같다. 송신 노드 $\mathrm{A}$ 는 토폴로지 테이 블에서 노드 $\mathrm{B}$ 의 정보를 확인한다. 표 2 의 "Node

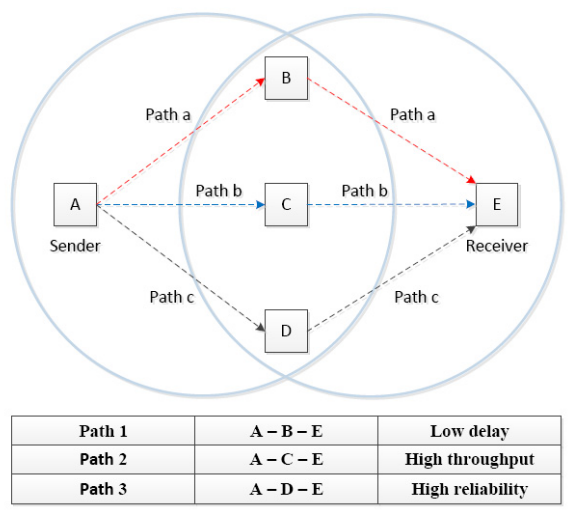

그림 7. 경로 선택 방법 개념도

Fig. 7. Route setting method conceptual diagram
Predecessor"의 주소가 노드 $\mathrm{A}$ 를 지정하는 테이블을 검색하여 $\mathrm{A}-\mathrm{B}$ 구간의 지연시간을 확인한 후, 노드 $\mathrm{E}$ 의 정보를 확인한다. 표2의 "Node Predecessor"의 주 소가 노드 B를 지정하는 테이블을 검색하여 B-E구간 의 지연을 확인한 후, 최종 지연을 계산한다. 경로 2 와 경로 3 을 순차적으로 지연을 계산하고, 최종적으로 경 로 $1,2,3$ 의 최종 지연을 비교하여 가장 낮은 지연을 갖는 경로를 선택한다. $\mathrm{T}$ 비트가 설정 $(\mathrm{T}=1)$ 된 경우는 높은 처리량을 가지는 경로를 선택한다. 경로 별 처리 랑을 산출하는 과정도 지연시간의 산출과 동일하다. 토폴로지 테이블에서 경로를 구성하는 각 노드들의 정보로부터 노드 별 누적 처리량을 확인한 후, 해당 경로의 최종 누적 처리량 산출할 수 있다. $\mathrm{R}$ 비트가 설정 $(\mathrm{R}=1)$ 된 경우에는 높은 신뢰성을 가지는 경로를 선택한다. 경로 별 신뢰성을 산출하는 과정은 토폴로 지 테이블에서 경로를 구성하는 각 노드들의 정보로 부터 신뢰성을 확인하고, 해당 경로의 최종 신뢰성을 산출한다.

제안한 DTR 기반 다중 경로 선택 알고리즘은 MIL-STD-188-220 프로토콜 인트라넷 계층의 프레임 생성 절차를 준수하여야 하고, 이때 생성된 경로 정보 는 인트라넷 헤더에 포함되어야 한다.

\section{III. 성능평가 및 분석}

본 장에서는 제안된 알고리즘의 성능을 평가한다. 성능평가 시나리오는 전차대대의 운용환경을 모의하 여 전차대대의 소대망과 대대망을 구성하였다.

트래픽 적용은 전술응용체계 정보유통량(IER: Information Exchange Requirement) 및 판별된 $\mathrm{KVMF}$ 메시지를 기반으로 예상 트래픽 모델을 구현 하였다. 성능평가를 위한 시뮬레이션은 OPNET을 활 용하여 수행하였다 ${ }^{[1]}$. 소대망은 4 개의 노드로 구성되 며 단일망으로 운용된다. 전차대대는 대대 1 개, 중대 3 개, 소대 9 개의 총 40 개 노드로 구성된다. 각 제대별 서로 다른 채널로 운영된다.

\section{1 소대망 시뮬레이션}

\subsection{1 소대망 구성}

소대망 시나리오는 그림 8 과 같이 4 개의 노드로 구 성된다. 노란색 박스에 있는 노드는 소대장 역할을 수 행하고 나머지 노드들은 소대원 역할을 수행한다. 기 본적으로 그림 8 의 왼쪽과 같이 1 홉을 구성하지만 작 전 수행에 따른 이동성으로 2 3 홉까지 변경될 수 있 


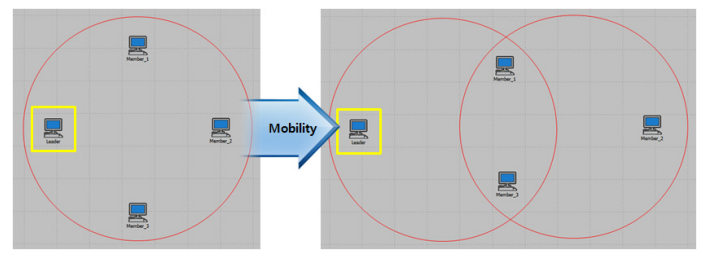

그림 8. 소대망 시나리오

Fig. 8. Platoon Network Scenario

다. 그림 8 의 오른쪽과 같이 구성되면 소대장과 가장 멀리 있는 소대원과는 다중 경로가 존재한다. 제안한 알고리즘의 성능을 확인하기 OPNET에서 제공하는 "Failure/Recovery" 노드를 사용하여 특정 경로의 품 질을 악화시켰다. "Failure/Recovery"는 시뮬레이션 중에 한개 또는 복수개의 링크에 대하여 일정 시간 동 안 사용하지 못하도록 하는 기능을 수행한다. 본 단일 망 시뮬레이션의 총 시간은 12 시간이며, 2 4시간 동 안은 상위 노드의 경로를 폐쇄하고, 8 10시간 동안은 하위 노드의 경로를 폐쇄하였다.

\section{1 .2 트래픽 설정}

본 시뮬레이션에서 설정된 트래픽 종류는 표 4와 같다. 적용된 트래픽은 " $\mathrm{KVMF}$ 전술데이터링크 개 발" 에 적용된 트래픽을 기반으로 한다. Type 3 메시 지는 DTR 요구사항을 반영할 수 있도록 DTR 비트를 설정하였다.

소대망 시뮬레이션에 적용된 계층별 파라미터 구성 을 표 5 에 나타내었다.

각 계층의 파라미터는 MIL-STD-188-220C 표준 문서의 기본 값을 정의하였으며, 물리계층의 파라미터 는 $\mathrm{FM}$ 무전기의 실측 값을 적용하였다. 네트워크 접 근 방법은 R-NAD를 적용하였다. 표준의 R-NAD를 그대로 적용하는 경우 멀티 홉 환경에서 동기 문제가 발생할 수 있다. 서로 다른 홉 사이에서 중계 기능을

표 4. 트래픽 조건 (소대망)

Table 4. Traffic conditions (Platoon Network)

\begin{tabular}{c|c|c|c|c|c}
\hline $\begin{array}{c}\text { Message } \\
\text { Type }\end{array}$ & $\begin{array}{c}\text { Type/ } \\
\text { Priority }\end{array}$ & $\begin{array}{c}\text { Period } \\
{[\mathrm{sec}]}\end{array}$ & $\begin{array}{c}\text { Size } \\
{[\mathrm{bit}]}\end{array}$ & $\begin{array}{c}\text { DTR } \\
\text { Setting }\end{array}$ & $\begin{array}{c}\text { Transmission } \\
\text { Direction }\end{array}$ \\
\hline $\begin{array}{c}\text { Battle Report } \\
\text { (교전보고) }\end{array}$ & $\begin{array}{c}\text { Type 3/ } \\
\text { Urgent }\end{array}$ & $900 \sim 2400$ & 98 & 001 & $\begin{array}{c}\text { Leader } \rightarrow \\
\text { Member }\end{array}$ \\
\hline $\begin{array}{c}\text { Intelligence } \\
\text { Report } \\
\text { (첩보보고) }\end{array}$ & $\begin{array}{c}\text { Type 3/ } \\
\text { Priority }\end{array}$ & $900 ~ 2400$ & 2206 & 010 & $\begin{array}{c}\text { Member } \rightarrow \\
\text { Leader }\end{array}$ \\
\hline $\begin{array}{c}\text { Entity Data } \\
\text { (개체데이터) }\end{array}$ & $\begin{array}{c}\text { Type 3/ } \\
\text { Priority }\end{array}$ & $900 ~ 2400$ & 2206 & 100 & $\begin{array}{c}\text { Member } \rightarrow \\
\text { Leader }\end{array}$ \\
\hline $\begin{array}{c}\text { Position Report } \\
\text { (위치보고) }\end{array}$ & $\begin{array}{c}\text { Type 1/ } \\
\text { Routine }\end{array}$ & 60 & 250 & 000 & 양방향 \\
\hline
\end{tabular}

표 5. 소대망 파라미터 설정

Table 5. Platoon Network parameters setting

\begin{tabular}{c|c|c}
\hline Layer & Parameter & Value \\
\hline \multirow{4}{*}{ Intranet } & Topology Update Period & $90 \mathrm{sec}$ \\
\cline { 2 - 3 } & $\begin{array}{c}\text { Topology Update } \\
\text { Message Priority }\end{array}$ & Routine \\
\cline { 2 - 3 } & Intranet ACK Timer & $60 \mathrm{sec}$ \\
\cline { 2 - 3 } & Intranet Retransmission Count & 2 \\
\hline \multirow{4}{*}{ Data Link } & NAD & R-NAD \\
\cline { 2 - 3 } & Data Link Retransmisson Count & 2 \\
\cline { 2 - 3 } & FEC/TDC & Enabled \\
\hline \multirow{4}{*}{ Physical } & Bandwidth & $25 \mathrm{kHz}$ \\
\cline { 2 - 3 } & Data Rate & $4800 \mathrm{bps}$ \\
\cline { 2 - 3 } & MTT & $10^{-6}$ \\
\hline
\end{tabular}

수행하는 노드는 각 홉에서 다르게 설정되는 NAD 타 이밍에 의하여 동기를 잃을 수 있으며, 이는 현재 표 준에서 구현상의 쟁점 중 하나로 인식되고 있다. 이를 해결하기 위해서 실제 시스템에는 다중 NAC (Network Access Control) 등의 방안을 적용하고 있 다. 본 연구에서는 소대망 환경에서는 단일 채널로 운 영되기 때문에 MIL-STD-188-220 표준과 같은 방법 을 적용하였으며, 발생가능성이 있는 홉 간 동기 문제 를 최소화하기 위해 R-NAD 산출 시 최대 범위를 홉 당 노드 수가 아닌, 채널(동일 주파수 대역) 내의 노드 수를 적용하여 동기 문제 발생 가능성을 최소화 하고 자 하였다. 다만, 동일 채널내의 노드 수가 증가하는 경우 중계 노드의 송신기회가 감소할 가능성이 있다. 본 연구에서 대대망은 다중 NAC 기능을 적용하였다.

\subsection{3 성능평가 결과}

시뮬레이션 성능은 모든 노드에서 수집하였고, 토 폴로지 구성에 따라 1홉부터 최대 2홉까지 성능 결과 가 측정된다. 제안한 알고리즘과 MIL- STD-188-220 표준 방법을 비교하였으며, 사용된 메시지는 제안한 알고리즘을 적용받는 Type 3 메시지(교전보고, 첩보 보고, 개체데이터)와 적용받지 않는 Type 1 메시지(위 치보고)로 구분하였다.

그림 9는 소대망 지연시간으로, Type 1 및 Type 3 메시지 모두 제안한 알고리즘의 평균 지연시간이 작다.

지연시간의 결과를 보면 제안한 알고리즘의 Type 3 을 제외하고는 fluctuation이 발생하였다. 소대망의 경우 4 개의 노드로 구성되어 통계를 측정하는 모집단 의 수가 적고, 2 홉으로 전송을 수행하는 구간은 NAD 타이밍을 적어도 2 번을 수행하며, 1 홉으로 전송을 수 행하는 구간은 NAD 타이밍을 1 번 수행하여 수신 시 간의 차이가 있기 때문이다. 특히, 경로가 단절되는 


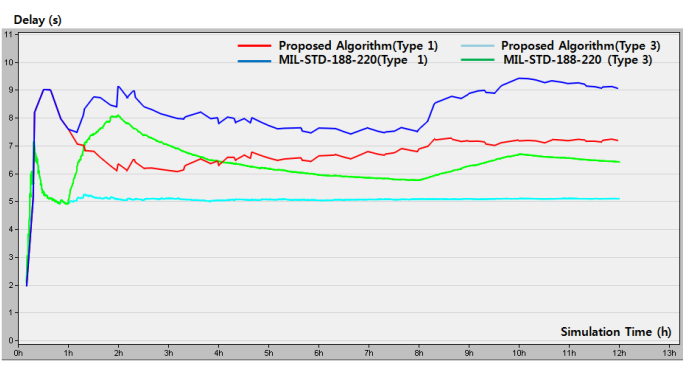

그림 9. 소대망 지연시간

Fig. 9. Platoon network delay time

시간에서 표준 방식은 경로의 품질 저하를 감지하지 못해 Type 3 메시지는 반복적으로 단절 경로를 선택 하며, 이는 재전송을 발생한다. Type 3 메시지의 잦은 재전송으로 인해 우선순위가 낮은 Type 1 메시지의 지연시간이 증가되는 현상이 발생한다. 반면에 제안한 알고리즘은 링크 단절을 초기 몇 번의 전송으로 감지 하기 때문에 단절 경로의 선택이 적다. 따라서, 제안 한 알고리즘의 Type 3 지연시간은 fluctuation이 발생 하지 않았지만, 표준 방식은 fluctuation이 발생하였 다. Type 1 메시지는 Type 3 결과에 영향을 받기 때 문에 제안한 알고리즘보다 표준 방식의 fluctuation 폭 이 더 큼을 확인할 수 있다.

이와 같이 MIL-STD-188-220 표준 방식은 링크 품 질 측정 및 운용방안의 부재로 인하여 폐쇄된 경로를 인식을 못하는 문제가 있다. 따라서, 링크가 폐쇄되는 구간에서 제안한 알고리즘에 비해 지연시간이 급격히 증가한다. 제안한 알고리즘은 링크 품질 설정 및 선택 알고리즘을 적용하여 초기 몇 번의 송신 시도를 통하 여 폐쇄 경로의 품질 저하를 반영하기 때문에 $\mathrm{QoS}$ 적 용에 따른 경로 선택 및 재송신 요청 감소로 인하여 성능이 향상됨을 알 수 있다.

그림 10 은 소대망의 성공확률을 나타낸 그림으로, 제안한 알고리즘의 성공확률이 표준 방법에 비해 높

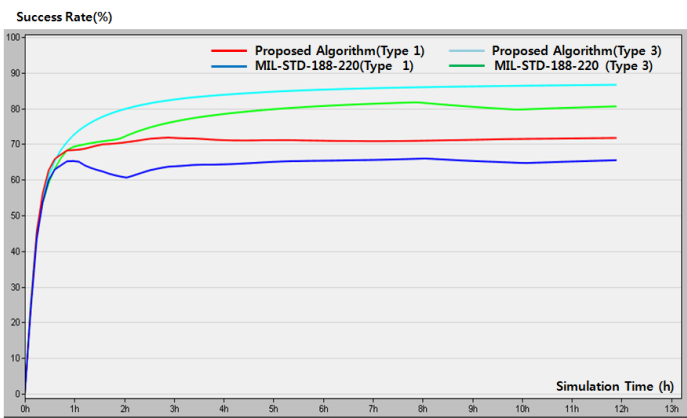

그림 10. 소대망 성공확률

Fig. 10. Platoon network success rate
다는 것을 알 수 있다. Type 3 메시지는 재전송을 수 행하여 Type 1 메시지에 비하여 평균 성공확률이 높 으며, 지연시간과 마찬가지로 링크가 폐쇄되는 시간에 성공확률이 감소하였다.

그림 11 은 소대망의 처리량 결과 그래프이다.

제안한 알고리즘이 MIL-STD-188-220 표준 방법 에 비하여 처리량이 높으며, 이는 표준 방식의 경우 링크가 폐쇄를 감지할 수 없어 성능이 감소하기 때문 이다. 본 시뮬레이션과 같이 링크가 일시적으로 폐쇄 되는 시나리오에서 기존의 표준 방식으로 전송을 수 행하는 경우 링크 폐쇄에 따른 품질 감소를 감지하지 못해 폐쇄된 링크를 반복하여 선택하고, 이로 인해 재 전송 및 전송 실패가 빈번히 발생하여 망의 성능이 감 소한다. 반면, 제안한 알고리즘을 적용하는 경우 각 경로의 DTR 특성을 측정하여 경로 폐쇄 시 경로의 품질 감소를 빠르게 감지하여 대체 경로를 선택함으 로써 성능 감소를 줄일 수 있다.

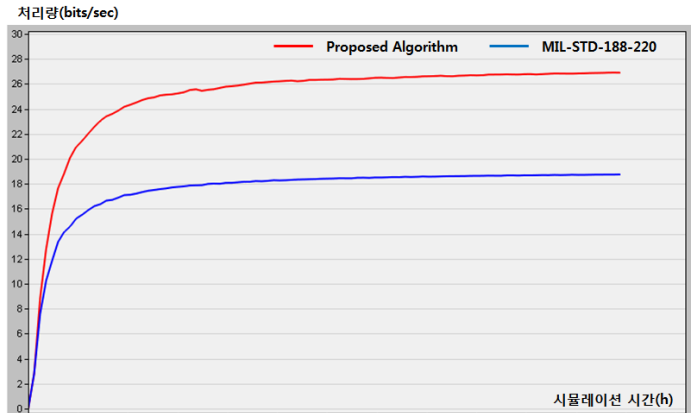

그림 11. 소대망 처리량

Fig. 11. Platoon network throughput

\section{2 대대망 시뮬레이션}

본 절에서는 전차대대를 구성하여, 다수의 경로와 상대적으로 유통량이 증가한 시나리오에서 제안한 알 고리즘의 성능 평가를 수행하였다.

\subsection{1 대대망 구성}

그림 12 는 $\mathrm{KVMF}$ 기반 전차대대의 대대망 시나리 오 구성을 보여준다.

그림 12 의 검은색 박스는 각 중대를 나타내며, 중 대에 편성되지 않고 가운데 존재하는 노드는 대대장 의 역할을 수행한다. 대대장 노드와 함께 노란색 원에 존재하는 노드는 중대장 역할을, 중대장 노드와 함께 파란색에 속한 노드들은 소대장 역할을, 소대장 노드 와 함께 가장 자리에 빨간색 원에 속한 노드들은 소대 원 역할을 수행한다. 총 40 개의 노드로 구성되며 대대 


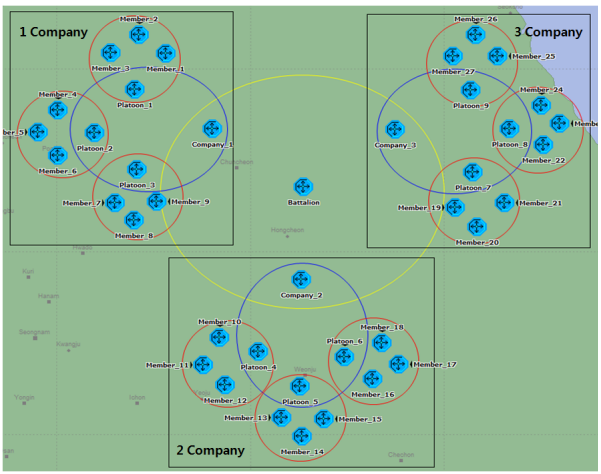

그림 12. 전차대대 무선망 시나리오

Fig. 12. Tank battalion wireless network scenario

장 노드 1 개, 중대장 노드 3 개, 소대장 노드 9 개, 소대 원 노드 27 개로 구성되어 있다.

본 시뮬레이션의 트래픽은 상위제대로 전송하는 경 우 “소대원 $\rightarrow$ 소대장 $\rightarrow$ 중대장 $\rightarrow$ 대대장”의 계층적 전송을 수행하며, 하위제대로 전송하는 경우에는 반대 로 “대대장 $\rightarrow$ 중대장 $\rightarrow$ 소대장 $\rightarrow$ 소대원”의 계층적 순서로 전송을 수행한다. 상위제대로 전송 시, 소대원 은 자신이 속한 소대의 소대장 이외에 2 개 소대장 노 드로의 대체 경로를 함께 생성한다. 하위제대로 전송 시에도 중대장은 최종 소대원 노드가 속해있는 소대 장 노드 이외에 대체 경로를 2개씩 갖도록 구성하고 있다. 즉, 상위제대 혹은 하위제대로 전송 시 목적지 까지 총 3 개의 경로가 존재한다. 제안한 알고리즘을 검증하기 위하여 각 중대의 소대장 노드 한 개는 비정 상적인 동작을 하도록 설계하였다. 1 중대(Company) 는 지연 특성에 영향을 주도록 전송 시 특정 크기의 지연을 갖도록 설계하였다. 2 중대는 처리량 특성에 영향을 주도록 수신된 메시지의 처리량을 감소하도록 설계하였으며, 3 중대는 신뢰성 특성에 영향을 주도록 임의로 ACK 메시지를 발생하지 않도록 설계하였다.

\section{2 .2 트래픽 설정}

본 시뮬레이션에서 설정된 트래픽은 총 4 개의 $\mathrm{KVMF}$ 메시지로 구성되며 표 6과 같다.

교전보고 메시지는 하위제대에서 상위제대로 전송 되는 Type 3 메시지이다. 우선순위는 Urgent이며 R 비트가 설정되어 높은 신뢰성을 요구한다. 첩보보고는 하위제대에서 상위제대로 전송되며, Type 3/Priority 의 특성을 가진다. $\mathrm{T}$ 비트가 설정되어 높은 처리량을 요구한다. 개체데이터는 상위제대에서 하위제대로 전 송되며, Type 3/Priority의 특성을 가진다. D 비트가 설정되어 짧은 전송 지연시간을 요구한다. 위치보고는
표 6. 트래픽 조건 (대대망)

Table 6. Traffic conditions (Battalion Network)

\begin{tabular}{c|c|c|c|c|c}
\hline $\begin{array}{c}\text { Message } \\
\text { Type }\end{array}$ & $\begin{array}{c}\text { type/ } \\
\text { Priority }\end{array}$ & $\begin{array}{c}\text { Period } \\
{[\mathrm{sec}]}\end{array}$ & $\begin{array}{c}\text { Size } \\
{[\mathrm{bit}]}\end{array}$ & DTR Setting & $\begin{array}{c}\text { Transmission } \\
\text { Direction }\end{array}$ \\
\hline $\begin{array}{c}\text { Battle } \\
\text { Report }\end{array}$ & $\begin{array}{c}\text { Type 3/ } \\
\text { Urgent }\end{array}$ & 600 & 336 & 001 & $\begin{array}{c}\text { low battalion } \rightarrow \\
\text { high battalion }\end{array}$ \\
\hline $\begin{array}{c}\text { Intelligence } \\
\text { Report }\end{array}$ & $\begin{array}{c}\text { Type 3/ } \\
\text { Priority }\end{array}$ & 300 & 272 & 010 & $\begin{array}{c}\text { low battalion } \rightarrow \\
\text { high battalion }\end{array}$ \\
\hline Entity Data & $\begin{array}{c}\text { Type 3/ } \\
\text { Priority }\end{array}$ & 300 & 280 & 100 & $\begin{array}{c}\text { high battalion } \rightarrow \\
\text { low battalion }\end{array}$ \\
\hline $\begin{array}{c}\text { Position } \\
\text { Report }\end{array}$ & $\begin{array}{c}\text { Type 1/ } \\
\text { Routine }\end{array}$ & 60 & $\begin{array}{c}460- \\
10210\end{array}$ & 000 & $\begin{array}{c}\text { high battalion } \\
\text { low battalion }\end{array}$ \\
\hline
\end{tabular}

양방향 모두 발생하며, Type 1 메시지로 요구되는 $\mathrm{QoS}$ 는 없다. 다만 노드의 역할에 따라서 발생하는 메 시지 크기가 다르다. 대대장 노드는 모든 하위제대의 위치정보를 포함하여 전송하고, 하위제대로 이동할수 록 포함하는 위치정보의 개수가 작아 크기가 감소한다.

\subsection{3 파라미터 설정}

전차대대 무선망 시뮬레이션에 적용된 계층 별 파 라미터 구성을 표 7과 같다. 응용계층에서 Machine $\mathrm{ACK}$ 를 사용하여 인트라넷 계층 및 데이터링크 $\mathrm{ACK}$ 를 사용하지 않으며, 위치보고 메시지는 취합보고를 수행하여 노드의 역할에 따라 위치보고 메시지의 크 기가 다르다. 또한 응용계층에서 496 byte 이상의 메 시지는 segmentation을 수행하여 하위계층으로 전송 한다. 대대망의 네트워크 접근 방법은 R-NAD를 적용

표 7. 전차대대 파라미터 설정

Table 7. Tank battalion parameters setting

\begin{tabular}{|c|c|c|}
\hline Layer & Parameter & Value \\
\hline \multirow{4}{*}{ Application } & Machine ACK Count & 2 \\
\hline & Machine ACK Timer & $60 \mathrm{sec}$ \\
\hline & Gathering Report Check & $\begin{array}{l}\text { Position Report } \\
\text { Message }\end{array}$ \\
\hline & $\begin{array}{l}\text { Application Layer } \\
\text { Segmentation Size }\end{array}$ & 496 byte \\
\hline \multirow{4}{*}{ Intranet } & Topology Update Period & $90 \mathrm{sec}$ \\
\hline & $\begin{array}{l}\text { Topology Update } \\
\text { Message Priority }\end{array}$ & Routine \\
\hline & Intranet ACK Timer & Disabled \\
\hline & $\begin{array}{c}\text { Intranet Retransmission } \\
\text { Count }\end{array}$ & Disabled \\
\hline \multirow{3}{*}{ Data Link } & NAD & R-NAD \\
\hline & $\begin{array}{c}\text { Data Link Retransmission } \\
\text { Count }\end{array}$ & Disabled \\
\hline & FEC/TDC & Disabled \\
\hline \multirow{4}{*}{ Physical } & Bandwidth & per channel $25 \mathrm{kHz}$ \\
\hline & Data Rate & $4800 \mathrm{bps}$ \\
\hline & MTT & $4 \mathrm{sec}$ \\
\hline & BER & $10^{-6}$ \\
\hline
\end{tabular}


하였다. 대대망은 각각의 망들이 서로 다른 채널을 사 용하고, 중계를 수행하는 노드는 멀티채널을 지원한 다. 중계를 수행하는 노드는 서로 다른 홉에 각 채널 로 동기를 맞추므로, 중계 기능 수행에 따른 동기 문 제가 발생하지 않으며, R-NAD 운용 시 송신 기회가 원활히 분배된다.

\subsection{4 성능평가 결과}

전차대대의 트래픽 특성상 시나리오를 구성하는 모 든 노드에서 트래픽이 발생하고 전송 경로가 다양하 기 때문에 망 전체에서 1 홉 기준으로 지연시간, 처리 량, 성공확률의 평균을 측정하여 제안한 알고리즘과 MIL-STD-188-220 표준 방법의 성능을 비교하였다. 성능 측정 메시지는 앞의 소대망 적용 시나리오와 동 일하게 Type 1, Type 3 메시로 구분하였다.

지연 시간을 나타내는 그림 13을 보면 Type 1 메 시지와 Type 3 메시지 모두 제안한 알고리즘의 평균 지연시간이 짧다. 본 시뮬레이션은 그림 12 의 1 중대 에서 중대장 노드 한 개가 특정 지연시간을 더하도록 설정되었다. QoS 필드의 D 비트가 설정된 경우 제안 알고리즘은 초기의 몇 번의 송신 시도를 통하여 지연 특성을 판단할 수 있다. 지연시간이 긴 경로를 우선적 으로 선택하지 않기 때문에 표준 방법에 비하여 지연 시간이 낮게 측정되었다.

그림 14는 메시지 Type 별 성공확률 그래프이다. 제안한 알고리즘의 성공확률이 표준 방법에 비하여 높으며, 특히 Type 3 메시지는 재전송을 수행하여 Type 1 메시지에 비하여 평균 성공확률이 높다. 그림 12 의 3 중대에서 중대장 노드 한 개가 임의로 $\mathrm{ACK}$ 를 발생하지 않도록 설정되었다. $\mathrm{QoS}$ 필드의 $\mathrm{R}$ 비트가 설정된 경우 제안 알고리즘은 신뢰성 특성을 판단하 여 메시지 전달확률이 낮은 경로를 우선적으로 선택 하지 않는다.

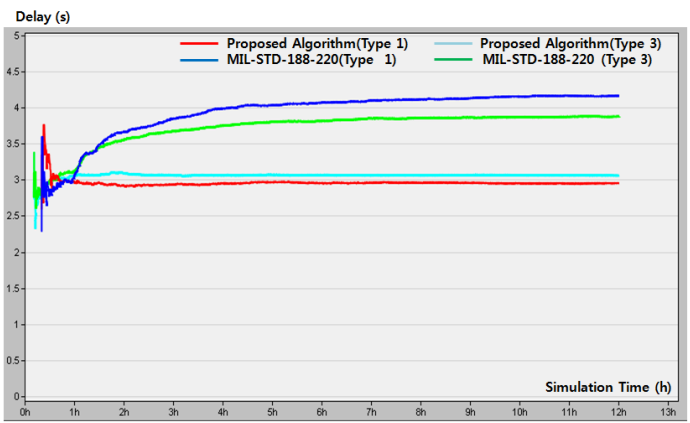

그림 13. 대대망 지연시간

Fig. 13. Battalion network delay time

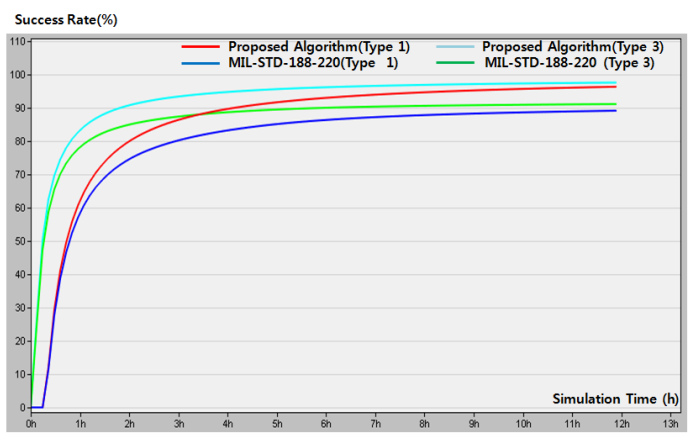

그림 14. 대대망 성공확률

Fig. 14. Battalion network success rate

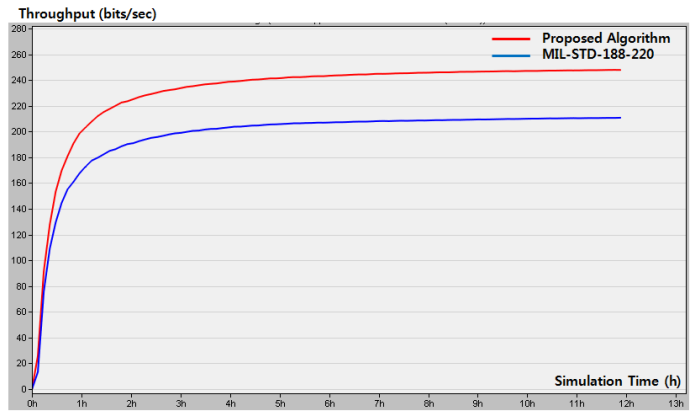

그림 15. 대대망 처리량

Fig. 15. Battalion network throughput

그림 15 는 알고리즘 별 처리량의 변화 그래프이다. 그림 12 의 2 중대에서 중대장 노드 한 개가 수신된 메시지 처리량을 감소시키도록 설정되었으며, 제안한 알고리즘의 처리량이 표준 방법에 비하여 높다. $\mathrm{QoS}$ 필드의 $\mathrm{T}$ 비트가 설정된 경우 제안 알고리즘은 처리 량 특성을 판단하여 높은 처리량을 갖는 경로를 우선 적으로 선택한다. 처리량의 경우 Type 1 메시지가 Type 3 메시지에 비하여 높게 나타나기 때문에 전체 처리량으로 표현하였다.

본 논문에서와 같이 다양한 특성을 갖는 다중 경로 시나리오에서 기존의 MIL-STD-188-220 표준 방식으 로 전송을 수행하는 경우 DTR 특성이 좋지 않은 경 로로 전송을 반복적으로 시도하여 망 전체의 성능이 감소한다. 반면, 제안한 알고리즘을 적용하는 경우 각 경로의 DTR 특성을 저장하고 있어 서비스가 요구하 는 $\mathrm{QoS}$ 를 만족할 수 있는 최적의 경로를 선택할 수 있기 때문에, 망 전체의 성능이 향상 된다.

\section{IV. 결 론}

본 논문에서는 토폴로지 변화가 많고, 운용 정책에 
따라 상이한 $\mathrm{QoS}$ 를 요구하는 서비스가 다량으로 통 신망을 차지하는 $\mathrm{NCW}$ 환경을 가정하여 기존의 MIL-STD-188-220 프로토콜에서 인트라넷 계층이 수행하는 송신지와 목적지 사이에 다중경로 발생시 $\mathrm{QoS}$ 를 최대한 보장하기 위해 DTR 비트를 활용하는 기법을 제안하였다.

링크에 폐쇄구간이 발생하였을 때 제안한 DTR 비 트를 활용한 기법을 적용하면, 기존 MIL-STD-188220 프로토콜 대비 데이터 송신에 대해 종단 간 지연 을 감소시켜주고 성공률 또한 증대되어 네트워크 성 능이 향상됨을 확인하였다. 다만, 본 연구에서 제안 하는 기법은 Type 3 메시지가 다량으로 존재하는 네 트워크 운용 환경에서 적용가능하며, Type 1 메시지 가 주로 운용되는 네트워크에서는 적용하기가 어려운 제한사항이 있다. 향후에 Type 1 메시지가 주로 존재 하는 네트워크 상황에서도 링크 품질을 제공할 수 있 는 방안에 대한 연구가 진행되어야 할 것이다.

\section{References}

[1] AK Cebrowski, et. al, "Network-centric warfare: Its origin and future," in Proc. US Naval Inst., Jan. 1998.

[2] K. G. Lee, S. J. Lee, Y. G. Kim, and K. H. Kwon, "A study for hop count on the ad-hoc of wireless communication," in Proc. KICS Int'l Conf. Commun. 2011 (KICS ICC 2011), pp. 431-432, Seoul, Korea, Nov. 2011.

[3] Y. S Yang and T. B. Choi, "A study on operational effectiveness analysis about KVMF message transmission by the current FM radio," in Proc. KICS Int'l Conf. Commun. 2010 (KICS ICC 2010), pp. 579-580, YoungPyong, Korea, Nov. 2010.

[4] C. Y. Cho, J. P. Lee, C. H. Kwon, and H. J. Cho, "A study on dynamic message processing for KVMF messages based on KVID," J. JCN, vol. 37, no. 2, pp. 173-180, Feb. 2012.

[5] MIL-STD-188-220D "Digital message transfer device subsystems," DoD, Sept. 2005.

[6] D. J. Thuente, "Improving quality of service for MIL-STD-188-220C," in Proc. Military Commun. Conf., pp. 383-844, Oct. 2001.

[7] N. S. Seo, J. W. Joo, and D. W. Jang, "A performance analysis of CSMA in wireless networks based on MIL-STD-188-220," $J$. $J C N$, vol. 37, no. 11, pp. 1129-1137, Nov. 2012.

[8] D. W. Kim, J. W. Jung, J. S. Lim, and J. I. Choi "A modified MAC protocol for reducing delay time of urgent message in MIL-STD188-220D networks," in Proc. KICS Int'l Conf. Commun. 2011 (KICS ICC 2011), pp. 230-230, Seoul, Korea, Nov. 2011.

[9] M. J. Kim, H. S. Leem, D. K. Sung, H. J. Lee, and Y. C. Son "Data link performance evaluation of an ad-hoc based on MIL-STD188-220C Standard," in Proc. KICS Int'l Conf. Commun. 2009 (KICS ICC 2009), pp. 843-844, Jeju Korea, Jun. 2009.

[10] M. J. Ryan and M. R. Frater, Tactical communications for the digitized battlefield, Artech House, 2002.

[11] K. H. Kwon, J. J. Hwang, H. S. Jeong, W. G. Lim, and Y. D. Yoon, "A method of implementing gateway model utilizing remote interrupts for interworking of a simulator with multiple real systems," J. KICS, vol. 38C, no. 1, pp. 57-63, Jan. 2013.

\section{권 구 형 (Koo-Hyung Kwon)}

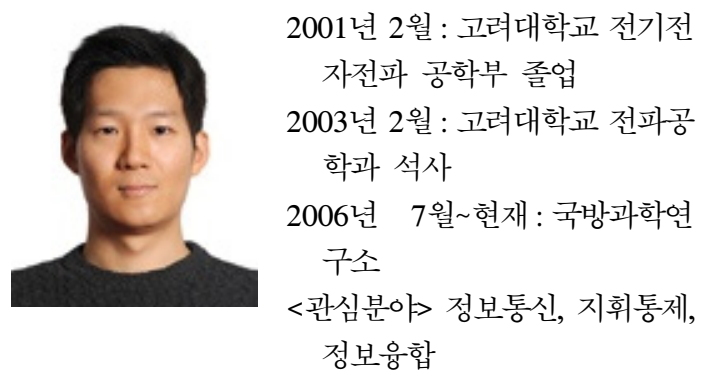


정 현 숙 (Hyun-Sook Jeong)

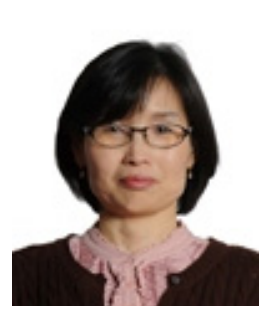

1993년 2월 : 숭실대학교 전자계 산학과 졸업

1995년 2월 : 숭실대학교 정보과 학대학원 석사

1999년 현재 : 국방과학연구소

<관심분야> 소프트웨어공학, 정 보통신

임 원 기 (Won-Gi Lim)

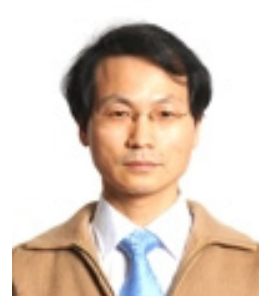

1994년 2월 : 건국대학교 전자계 산학과 졸업

1996년 2월 : 건국대학교 컴퓨터 공학과 석사

1999년 현재 : 국방과학연구소

<관심분야> 전술데이터링크, 실 시간시스템

\section{윤 영 득 (Young-Deuk Yoon)}

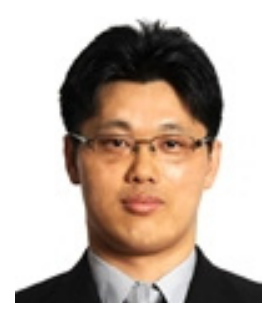

1998년 2월 : 고려대학교 전파

\section{공학과 졸업}

2000년 2월: 고려대학교 전파 공학과 석사

2002년 1월 현재: 국방과학연구소 <관심분야> 통신공학, 지휘통

제, 네트워크

\section{김 상 수 (Sang-Soo Kim)}

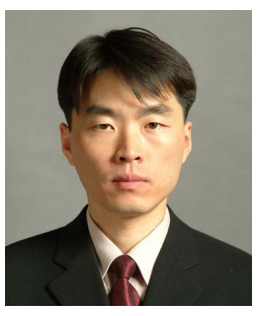

1997년 8월 : 경북대학교 전자공 학과 졸업

2003년 8월 : 경북대학교 컴퓨터 공학과 석사

2003년 8월 현재: 국방과학연구소 <관심분야> 전술데이터링크, 네 트워크

\section{이 상 진 (Sang-Jin Lee)}

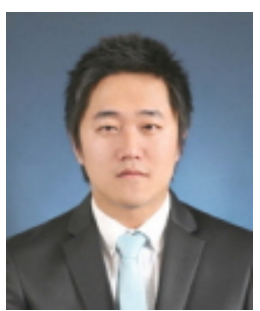

2011년 2월 : 광운대학교 전자 통신공학과 석사

2011년 2월 현재 : (주)유큐브

기술연구소 연구1실 대리

<관심분야> 국방 $\mathrm{M} \& \mathrm{~S}$, 센서

네트워크 